\title{
Antun Gustav Matoš i Đakovo
}

\begin{abstract}
Curić Mirko, Antun Gustav Matoš i Đakovo (Antun Gustav Matoš and Đakovo). „Poznańskie Studia Slawistyczne” 7. Poznań 2014. Publishing House Science and Innovate, pp. 79-90. ISBN 978-83-63795-79-5. ISSN 2084-3011.
\end{abstract}

The paper deals with the relationship between Antun Gustav Matoš and the most important people of the town's cultural and political life at the turn of the $19^{\text {th }}$ into $20^{\text {th }}$ century. The relationship between Matoš and the town Đakovo is considered from two perspectives: the first being the perspective of Matoš, which is based on his two travel accounts and numerous writings about Đakovo, i.e. the Bishop of the Diocese of Đakovo, Josip Juraj Strossmayer; the second perspective is that of Đakovo-based writers and considers their attitudes towards Matoš, with a special regard to the Bishop Strossmayer. The relationship between Antun Gustav Matoš and the Bishop Strossmayer was complex, even though it was, seemingly paradoxical, one-sided. Strossmayer was in many, ways an extraordinarily important person for Matoš, who wrote many texts about Strossmayer, for Strossmayer however, Matoš was only one among many young Croatian writers who were asking him for help and wrote about him. Strossmayer refused to provide Matoš with patronage, therefore the aim of this paper is to establish the reasons behind that decision, and determine why Croatia's most prominent patron could not, or refused to, acknowledge one of Croatia's most important writers.

Keywords: Đakovo; Antun Gustav Matoš; Josip Juraj Strossmayer; travel account; Croatian Party of Rights; Croatian Moderna; politics and literature; culture

\section{Uvod}

Rad se bavi odnosom Antuna Gustava Matoša spram Đakova te najznačajnijih ličnosti đakovačke kulturne i političke scene na prijelazu iz XIX. u XX. stoljeće. Navedeni se odnos promatra iz dviju perspektiva. Prva je Matoševa, utemeljena na dvama putopisnim zapisima Antuna Gustava 
Matoša o Đakovu te na njegovim brojnim tekstovima u kojima se bavi Đakovom, odnosno đakovačkim biskupom Josipom Jurjem Strossmayerom, dok se druga bavi odnosom đakovačkih autora spram Matoša, s naglaskom na biskupa Strossmayera. Strossmayer, naime, odbija dati mecenatsku potporu Matošu, pa rad pokušava otkriti razloge takvog postupka, odnosno odgovoriti na pitanje zašto Strossmayer, najveći hrvatski mecena, ne prepoznaje ili ne želi prepoznati jednoga od najvećih hrvatskih književnika.

\section{Matoš vs. Strossmayer}

Đakovo je hrvatski grad s oko 28000 stanovnika ${ }^{1}$, smješten u Osječko-baranjskoj županiji, devetnaesti po broju stanovnika u Hrvatskoj. Sjedište je velike Đakovačko-osječke nadbiskupije te Slavonske crkvene pokrajine. U vrijeme biskupa Strossmayera Đakovo je proživljavalo svoje ,zlatno doba", odnosno, bio je to grad od izuzetne važnosti u hrvatskoj kulturi i politici, ali i u okolnim zemljama, pa čak i u Poljskoj, o čemu svjedoči djelo Piotra Żureka Poljska i Poljaci u životu Josipa Jurja Strossmayera. Biskup Strossmayer stvorio je grandiozno djelo kojim je mnoštvo Strossmayerovih suvremenika, tako i pjesnika, bilo iskreno zadivljeno ${ }^{2}$. Među takvima našao se i A.G. Matoš, iako vatreni pravaš i starčevićanac - što je često značilo jasnu opreku, omalovažavanje, čak i mržnju spram Strossmayera i njegova djela - u brojnim tekstovima priznaje Strossmayeru veličinu i zasluge, napose za hrvatsku kulturu. Odnos Antuna Gustava Matoša i biskupa Strossmayera bio je iznimno kompleksan, iako, naizgled paradoksalno, zapravo

${ }^{1}$ Grad Đakovo danas je administrativna jedinica koja se sastoji od grada Đakova i osam prigradskih naselja, točnije okolnih sela: Piškorevaca, Novih Perkovaca, Budrovaca, Đurđanaca, Piska, Kuševca, Ivanovaca i Đakovačkih Selaca.

${ }^{2}$ Kao ilustracija neka posluži odlomak iz životopisa Josipa Kosora koji je kraće vrijeme živio i radio u Đakovu: „U izražaju njegova lica vidila se silna volja, božanska neustrašivost i snaga da sugerira i hipnotizira me kud njegovi visoki ideali ciljaju (...). Gledajući ga tako ćutio sam neki viši ponos zbog njega i ugodno sjećanje kako me je on u Otoku u skromnoj, prečistoj, nadahnutoj nutrini crkve sa svetim slikama, drvenim kipovima i oltarima kao dijete, sa ostalom seoskom djecom krizmao (...). Ovaj momenat pripisivao sam sreći i sretnom ulazu i prolazu kroz džunglu, pustoš i Saharu života pomišljajući, e da, događaj je to biti krizman od velikog biskupa; nehote sjećajući se stihova Petra Preradovića: «Usprotivi se Rimu jakom, / sveslavenstva posta junakom, / oj narodni ugodniče / ugodnio tebi Bog.../»" (Kosor 1990: 75). 
jednostran. Dok je za Matoša Strossmayer u mnogim pogledima iznimno važna ličnostte o njemu piše i brojne tekstove, za ostarjelog je Strossmayera Matoš tek jedan od mladih i mnogobrojnih hrvatskih umjetnika koji mu se obratio za pomoć i koji je o njemu nešto (na)pisao. Matoš je u vrijeme Strossmayerova života (Strossmayer umire 1905., dok je Matoš još „izvan zakona”) ne samo vojni bjegunac i čovjek s ruba društva, makar i nadaren i priznat umjetnik, već i pravaš, starčevićanac, a prijepor između Strossmayera i Starčevića jedan je od mitskih i čini se do danas nezavršenih sukoba hrvatske političke povijesti.

Strossmayer je, dakle, česta tema Matoševih tekstova, dok u obrnutom smislu gotovo i nema referenci, a najvažnija je ona na poleđini pisama iz 1896., gdje Matoš traži financijsku potporu od biskupa. „Ne može ništ biti. J.J.B.” (Srakić 1982: 153-156), zapisuje rezolutno biskup. Pismo Matoš piše u Beogradu „20. septembra 1896.” te u njemu izražava svoje divljenje Strossmayerovu djelu, napose mecenatstvu spram umjetnika, te ga, shodno tome, moli za financijsku pomoć jer je u Beogradu u teškoj oskudici. Završava riječima: „Preporučujuć se Vašim molitvama za Hrvate - ostajem Vaše preuzvišenosti oduševljen poštovalac" (Srakić 1982: 153-156). Strossmayer kategorički odbija dati potporu mladom umjetniku, vojnom bjeguncu, koji u Beogradu krpa kraj s krajem, a u gladnom mu se očajanju prikazuje lik ,prvog narodnog biskupa”, velikog mecene, podupiratelja umjetnosti i umjetnika. No od pomoći, unatoč laskavim rečenicama, nije bilo ništa.

Vlatko Dolenčić ${ }^{3}$, arhivar Središnjeg nadbiskupijskog arhiva, koji, među ostalim, radi i na sređivanju osobne korespondencije biskupa Strossmayera $^{4}$, potvrdio je kako je to jedino Matoševo pismo biskupu te kako u Arhivu nema kopije možebitnog Strossmayerova pismenog odgovora. Nije isključeno da je takvog pisma bilo, ali kod privatne se Strossmayerove korespondencije nisu pravile i čuvale kopije pisama, osim u iznimnim situacijama. Formulacija odbijanja bila je uobičajena i Dolenčić je nalazi na brojnim pismima privatnih molitelja koja je biskup primao. Biskupova zabilješka „Ne može ništ biti!” s potpisom J.J.B. bila je uputa tajniku koji je

${ }^{3}$ Razgovor i uvid u arhivsku građu obavljen 15. travnja 2014.

${ }^{4}$ Riječ je o korespondenciji koja nije do kraja sređena. Do sada su obrađena pisma s prezimenima autora s početnim slovima od a do d. Ipak, pokazuje veliki broj molitelja iz cijele ondašnje Monarhije, ali i inozemstva. 
pisao odgovor što ga je biskup kasnije samo potpisao. U nekoliko slučajeva biskup je nadopisao i „Žalibože!”, što je ne samo izraz žaljenja jer ne može udovoljiti zamolbi, već i naznaka u kojem smjeru tajnik treba formulirati odgovor. Iako odbijenica Matošu ne predstavlja izuzetak koji bi značio nekakav posebno negativan odnos biskupa prema Matošu, već je i znak slabije materijalne situacije u Biskupiji, nekim drugim moliteljima odnosno moliteljicama te iste godine Strossmayer ipak uvelike pomaže. Marija Jurić Zagorka mjesec dana nakon Matoša, 17. listopada 1896., piše pismo biskupu Strossmayeru moleći njegov zagovor za posao novinarke i materijalnu pomoć (Brešić 1997: 451). Zagorka dobiva posao u „Obzoru”, s 30 forinti tjedne plaće, a u uredništvu koje joj je izrazito nesklono doznaje da je to po preporuci važnog dioničara novina J.J. Strossmayera:

Još su mi pokazali pismo biskupa Strossmayera, upravljeno na ravnateljstvo Obzora, gdje sam biskup između ostalog piše: „(...) iz svih, po mene i mojem tajniku Mons. Čepuliću pročitanih članaka i dopisa u peštanske novine proizlazi nepobitno, da je gospodin Bog odlučio podieliti novinarski talent i ženi, (...) i zato neka ravnateljstvo odbaci sve predrasude i namjesti ovu ženu - koja je - kako se jasno razabire iz madjarskog pisma - odbila vrlo liepu ponudu u Budimpeštu iz idealističkih osjećaja" (Vukovac 2010: 256).

Na primjeru Zagorke vidljivo je koliko je Strossmayer i u poznim godinama lucidan i utjecajan. Potpomaže financijski Zagorkina djela kao što su Roblje ${ }^{5}$ i Vlatko Šaretić, iako ih kritika proglašava šund literaturom (Vukovac 2010: 262). Odnos prema Zagorki pokazuje koliko je Strossmayer mogao pomoći Matošu da je smatrao kako ovaj njegovu pomoć i pozornost zaslužuje.

Ne možemo točno ustvrditi je li Matoš dobio pismo s biskupovom odbijenicom, ali se to očito nije odrazilo na njegov odnos prema Strossmayeru. A da je on uglavnom ostao, netipično za pravaše, pozitivan, tvrdi i Krešimir Nemec u radu Pravaštvo i hrvatska književnost:

No kod pravih umjetnika, a to je Matoš nesumnjivo bio, ideologija nikada ne guta književnost pa ni Matoš nije dopustio da svoju pisanu riječ stavi u službu neke ideje,

\footnotetext{
5 Za tiskanje Zagorkinog Roblja Strossmayer plaća 100 forinti (Pavić, Cepelić 2013: 931).
} 
pa čak ni one u koju je svim srcem vjerovao. Vidi se to već i u odnosu prema Strossmayeru, političkom protivniku o kojem nije govorio jezikom mržnje kao njegovi pravaški prethodnici, već ga je osvjetljavao s više strana, često i s dubokim poštovanjem i razumijevanjem za njegove postupke (Nemec 2007: 119-129).

Zanimljivo, Matoš se najintenzivnije bavio Strossmayerom nakon njegove smrti: „U razdoblju od 1905. do 1914. A.G. Matoš je napisao brojne članke o biskupu Strossmayeru (često s polemičkim nabojem) tretirajući u njima niz problema koji su bili više ili manje vezani za ishodište misli na kojima počiva model uzora - Ante Starčević”, piše Branka Brlenić Vujić (2008: 531-540). Dubravko Jelčić tvrdi kako Strossmayer zauzima „neveliko, ali po vrijednosti zasebno, pa i počasno mjesto (...) u djelu najvećeg hrvatskog književnika na prijelazu stoljeća A.G. Matoša” (2008: 376).

U suprotnom smjeru većeg odjeka nije bilo, a zapravo je i ta činjenica jasan stav spram Matoša. U znamenitoj monografiji Matije Pavića i Milka Cepelića Josip Juraj Strossmayer (Pavić, Cepelić 2013) na preko tisuću stranica Matoš se ne spominje niti na jednom mjestu, iako je knjiga objavljena 1904., a obuhvaća ljude i događaje do 1900. Biskup je tada već starac, njegovo zanimanje za nove pojave u umjetnosti i književnosti zacijelo je mnogo manje nego ranijih godina, a, osim toga, „Strossmayer nije baš volio osobenjake i boheme, pogotovu ako su o njemu ovisili" tvrdi Krešimir Pavić (2008: 115-138). Stoga o Strossmayerovu odnosu spram Matoša možemo, zapravo, samo nagađati ili iz one mecenatske odbijenice na poleđini pisma izvoditi zaključke, iako je očito da je, u vrijeme kada pristiže Matoševa zamolba, tih odbijenica iznimno veliki broj. Čini se da Strossmayer Matoša i njegovo djelo nije poznavao niti je pokazivao značajniji interes da ga upozna, a tome u prilog nije išlo Matoševo pravaštvo i status vojnog bjegunca. Strossmayer u svom djelovanju, zapravo, nikada nije osporavao legitimitet carske vlasti, iako mu se znao suprotstaviti, kao u znamenitoj „Bjelovarskoj aferi” iz 1881., a znan je otkaz koji je Luka Botić dobio 1860. kada je kao biskupov notar odbio prisegnuti na vjernost caru.

Matoš pak o Strossmayeru izriče brojne sudove, ponekad i proturječne, a jedan je od najcitiranijih ovaj gdje je prikazan, a kako bi drugačije, nego u opreci spram Starčevića: 
Popunjavahu se, ali ne kao Schiller i Goethe, već kao suprotni karakteri i ekstremi koji se dodiruju. Starčević je bedemska planina, zatvorena, puna vuka i ličkog hajduka. Strossmayer je blaga i bogata slavonska ravnica. Stari ima znanje solidnije, Strossmayer opsežnije. Prvi je ekskluzivan, drugi tolerantan. Prvi je učitelj energije i mržnje (egzistencija žuči je opravdana), drugi je profesor ljubavi i poezije. Stari je stoik i velik prijatelj Muhamedov. Biskup je fini kršćanski epikurejac, nježan kao sv. Ivan, najdraži Spasiteljev učenik. Strossmayer je svjetski čovjek sa ponašanjem opata i virtuoza Liszta, ljubimac dama; Starčević je plebejac «hiperdemokratskog nosa» (Kovačić), divlji ikonoklast s obličjem Silena i djevičanstvom pustinjaka. Puritanac i katolik. Pazarište i Osijek. Literat, boem - i velikaš hrvatski i grof rimski. Jedan dervišina narodne pjesme, drugi biskup V. Hugoa. Oportunist i radikal. Cinik i retor. Mrzilac plastike i njen obožavalac. Veliki književnik Starčević prezire dangubice književničke; Strossmayer, obožavalac beletristike, nije književnik. Demokrat i aristokrat. Starozavjetni moral u demagoškom civilu i galilejska tolerancija u katoličkoj uniformi. Dva pretendenta kao Rousseau i Voltaire, Tolstoj i Turgenjev. Dva tipa našeg narodnog karaktera i naše cerebralnosti, i odsele se ne može roditi inteligentan Hrvat bez sličnosti s njima (Matoš 1976: 26).

Ovaj se rad neće baviti stavovima iznesenima u navodu, osim Matoševim zaključkom kako „Strossmayer, obožavalac beletristike, nije književnik", što, jednostavno, ne odgovara istini. U zadnje se vrijeme, pored brojnih Strossmayerovih odrednica, njemu često pridaje i ona - književnik. Naravno, ne onaj koji piše književnost u užem smislu - pjesme, priče, romane ili drame - ali je svoje mjesto u hrvatskoj književnosti zaslužio kao putopisac i esejist i prava je šteta što onaj putopisno-esejistički spisateljski žar, koji je kod njega vidljiv u sedamdesetim godinama 19. stoljeća, nije na sličan način nastavljen do kraja njegova života. Osim putopisa objavljenog u „Viencu” i biskupijskom „Glasniku”, u sedamdesetim godinama XIX. stoljeća nastaje njegova rasprava/ogled ${ }^{6}$ Stolna crkva u Djakovu (Strossmayer 1874a, Strossmayer 1874b: 5-18). To nije samo ogled o gradnji jedne veličanstvene crkve, već je i svojevrstan Strossmayerov crkveni, moralni, umjetnički, kulturni i nacionalni program, a slično je i s njegovim nizom tekstova - kulturološko-religioznih rasprava/ogleda - o freskama u đako-

${ }^{6}$ Tako ovaj tekst određuje Tadija Smičiklas, vjerojatno želeći i na taj način istaknuti Strossmayerovu učenost jer je rasprava učenija i time ,vrjednija” od ogleda (Smičiklas 1906: VII-VIII). 
vačkoj katedrali, objavljenima prvotno u biskupijskom „Glasniku”. Strossmayer je u svojim tekstovima informativan, piše s puno digresija i asocijacija, upućen je u građu o kojoj piše i čvrst u argumentaciji svojih stavova:

Sve što je Strossmayer napisao i ostavio objavljeno u različitim publikacijama ${ }^{7}$ od pseudonimnog političkog članka u Gajevim novinama pa do njegovih govora u Saboru i na svečanostima u Akademiji, tiskanima u Dnevnicima Sabora Trojedine Kraljevine ili u Radu (tadašnje) Jugoslavenske akademije znanosti i umjetnosti, putopisa u Šenoinu Viencu i korizmenih poslanica objelodanjivanih u đakovačkom Glasniku Biskupija bosanske i sriemske, nosi neizbrisivo obilježje njegove svestrane osobnosti. Kako smjelošću iznesenih ideja tako i sugestivnom intonacijom govorničke ornamentike, Strossmayer se pokazao piscem lapidarna izraza i okretnim govornikom, koji ima osjećaj i za dinamiku rečenice i za efektnu stilizaciju i za duhovite opaske i za neočekivane obrate (2008: 40),

tvrdi akademik Dubravko Jelčić, obrazlažući zašto Strossmayera smatramo (i) književnikom. Kao konačni dokaz kanonizacije biskupa Strossmayera na hrvatskom književnom Parnasu, služe svakako i dva toma edicije „Stoljeća hrvatske književnosti" priređivača spomenutog akademika Jelčića, pod nazivom Izabrani književni i politički spisi (Strossmayer 2005, 2006). Jasno je iz tih knjiga da Strossmayer pripada vještijim i nadahnutijim hrvatskim perima 19. stoljeća. Matoš to, možda, ne zna. Teško je prihvatiti i neke druge efektne Matoševe teze o Strossmayeru kao svojevrsnom hrvatskom Voltaireu s kojim ga povezuju „ladanjsko zatočeništvo” i „,tolerantan značaj” (Matoš 1967: 268).

\section{Matoš i đakovački političari i književnici}

Osim Strossmayerom, Matoš se bavi i drugim đakovačkim književnicima i političarima svoga vremena, a napose u dvama putopisima u kojima opisuje svoje pohode Đakovu 1906. (Matoš 1976: 153-154) i 1907. (Matoš 1967: 271-274). Prvi put dolazi inkognito, a drugi put nakon amnestije, kao slobodan čovjek. Matoš pokazuje solidno poznavanje političkih prilika

7 O množini novina i časopisa u kojima je Strossmayer objavljivao svoje radove svjedoči rad Strossmayerova ostavština u JAZU (Košćak 1960: 348-349). 
u Đakovu, a iskazuje i jasne književne stavove, napose na đakovačkom groblju gdje kao prve đakovačke književnike, relevantne u nacionalnom kontekstu, spominje Luka Botića i Nikolu Tordinca:

Groblje, provincijsko romantično groblje na uzvisici. Na lijevo kuće u bijeloj ljetnoj prašini, a na puškomet odavde visina katedrale, groba Biskupova, najljepšeg groba hrvatskoga. Jer tu, pored sjajnog Strossmayerovog i skromnog Tordinčevog groba, počiva pod sirotinjom gvozdenog, banalnog krsta Luka Botić, veliki karakter i jedini narodni naš romantik. Tri slavna groba na tako malom i banalnom prostoru. Koje naše provincijsko mjesto može se ponijeti takvim pokojnicima? (Matoš 1967: 272).

Poštovanje koje iskazuje spram ovih dvaju autora nije neočekivano jer je riječ o kanoniziranim piscima, napose o Botiću kojega se u Matoševo vrijeme svrstavalo uz bok Mažuraniću, Martiću ili Njegošu ${ }^{8}$. Nikola Tordinac bio je redoviti suradnik najvažnijih hrvatskih časopisa sve do svoje smrti 1888. godine. Matica hrvatska objavila mu je 1890. Odabrane crtice i pripovijesti (Tordinac 1890) koje je vjerojatno Matoš čitao. Među Tordinčevim je pripovijetkama i pripovijest Kožuh, objavljena nakon njegove smrti 1889. godine, koja je uvođenjem psiholoških elemenata u dramu dva zavađena brata, svojevrsna prednajava moderne čiji su tekstualni početci, kako se slažu književni povjesničari i teoretičari, Matoševa novela Moć savjesti i/ili Leskovarova novela Misao na vječnost. L. Botić i N. Tordinac, uz Jurja Tordinca, i danas se smatraju najznačajnijim đakovačkim književnicima.

Osim što spominje ova dva književnika, Matoš je u kontaktu sa sinom još jednoga đakovačkog autora, odvjetnika, političara i pjesnika Gjure Kovačevića ${ }^{9}$, ali, zanimljivo, Matoš o njemu piše samo kao o odvjetniku:

Nedjelja. Krumpirbal. Sjedim s rođakom i s limarom Čajkovcem. Pijemo. (...) Snažna momčina, povezane glave, krvavih ruku i prsiju, kočijaš opozicijskog agitatora Kovačevića (sina poznatog odvjetnika), žali nam se kako ga je čopor Švabova iz busije u mraku iznakazio kamenicama (Matoš 1967: 270).

${ }^{8}$ „Slavna su imena Pucić, Buzolić, Pavlinović, a nadasve Njegoš, Martić, Mažuranić. Znademo, da je i Preradović sa svojom Lopudskom siroticom zašao u kolo ovih pjesnika. U ovom milieu-u nikao je i pjesnik L. Botić i u njem se sav uzgojio. Dostojno stoji uz bok pjesniku Čengić-age, Gorskoga vijenca i Osvetnika" (Rittig 1908).

9 Više o Gjuri Kovačeviću u knjizi Moja perva i posliednja ljubav (Kovačević 2007). 
Teško je povjerovati kako Matoš nije znao za književni rad oca „,političkog agitatora Kovačevića" (Matoš 1967: 270), ali ga vjerojatno nije smatrao vrijednim piscem, iako je Kovačević bio i član Društva hrvatskih književnika od njegova osnutka 1900., a uvršten je kao autor s dvjema pjesmama $^{10}$ i u znamenitu Badalićevu Antologiju (1892: 19-20).

Cinično Matoš zapisuje kako od hrvatske književnosti u Đakovu dobro Živi samo knjižar - Židov Makso Bruck:

Knjižar, g. Makso Bruck, koji, kako čujem, ni danas ne umije pisati hrvatski, veliki „protekcionskind” prošle uprave, kojoj lifrovaše matrijal za urede, gazda Makso Bruck izdaje na veliko grozne funtromane, smetajući širenju zdrave i prave hrvatske literature. I kod nas još ima bezazlenjaka koji tvrde da se u Hrvatskoj ne da živjeti od književnosti! Evo i gospodin Max Bruck živi od nje, i da nije tako, gospodin Max Bruck bi se iselio iz đakovačke pitomine (Matoš 1967: 273).

Matoša posebno intrigiraju političke prilike u Đakovu. Tako u putopisu iz 1906. hvali odluku đakovačke oporbe da se ujedini oko Vatroslava Rač$\operatorname{kog}^{11}$, brata puno slavnijeg Strossmayerova suradnika i najboljeg prijatelja kanonika i povjesničara Franje Račkog, ali ponešto krivo razumije i tumači đakovačke političke prilike, odnosno idealizira u konačnici traljav izborni pokušaj. O tome piše povjesničar Branko Ostajmer (2005: 141).

Matoš je u Đakovu boravio nekoliko dana krajem kolovoza i početkom rujna iste godine, za vrijeme svoga ilegalnog boravka u Hrvatskoj. Upravo tada u Đakovu je bila u tijeku organizacija Hrvatskog sokola i Matoš je pozdravio te napore, posebno stoga što su u organizaciju bili uključeni pojedinci iz svih stranaka, osim „,mađaronske”. „Stekliši i pokretaši radili su kod prošlih izbora zajednički za opozicionalca gosp. Račkoga proti izabranom mađarolcu Švarcmajeru”, nastavlja Matoš u svom putopisu (1976: 153).

${ }^{10}$ To su pjesme Gjure Kovačevića Bezimena tuga i Moja djeva.

11 Vatroslav Rački rođen je 26. siječnja 1842. godine u Fužinama. Školovao se na Gospodarsko-šumarskom učilištu u Križevcima. Odmah po svršetku školovanja Rački se zaposlio kao šumar na vlastelinstvu Đakovačke biskupije. Već u drugoj polovici šezdesetih godina objavio je nekoliko stručnih i zapaženih članaka, da bi 1870. godine u Sisku izdao manju knjigu $O$ sječi $i$ gojenju šuma, koja predstavlja jednu od prvih šumarskih knjiga na hrvatskom jeziku. Rački je bio i jedan od pokretača „Šumarskog lista”. Neko vrijeme živi i u Zagrebu gdje je niz godina urednik hrvatskog „Šumarskog lista” i „Hrvatskog šumarskog koledara". Po umirovljenju, vraća se u Đakovo. Umro je 11. kolovoza 1917. godine. 
Zanimljivo je da Matoš uopće ne spominje svećenstvo koje je stajalo na čelu oporbe, a posebno je upitan navod o pokretašima.

Matoš u svojim dvama putopisima nabraja još nekoliko đakovačkih političara, a napose Slavka Cuvaja koji je odigrao važnu ulogu u đakovačkom političkom životu osamdesetih godina XIX. stoljeća, što se, nažalost, često zaboravlja u životopisima kontroverznog političara, gdje je ta važna epizoda za njegov uspon izostavljena. Matoš piše o svojevrsnom poniženju koje je na dvama saborskim izborima doživio Strossmayer od strane Cuvaja i njegovih suradnika:

Ne. Mi nemamo još ni danas zemljišta za eventualnog Voltairea. I Strossmayer bi bio kod nas iščeznuo u sveopćoj vulgarnosti, da mu ne bješe tih pustara, tih silnih šuma, toga gospodstva i blaga. I unatoč tom iznimnom, privilegiranom položaju, jednom ga je s izbora jednostavno izjurio nekakav Khuenov lakaj, po imenu Cuvaj. I taj subjekt, taj Cuvaj je i danas u službi, i to ne u sitnoj: on, Cuvaj, je veliki župan Like i Krbave (Matoš 1967: 268).

Matoš suosjeća sa Strossmayerom, velikanom koji bi bio uništen od „hrvatske mizerije”, možda onako kako su uništavali/uništili A.G. Matoša, da nije bio financijski neovisan. Tu zanimljivu epizodu Strossmayerova poniženja od strane Cuvaja opisao sam u priči Promicanje $i$ unaprjeđenje znanosti i umjetnosti u Hrvatskoj i Slavoniji za banovanja Dragutina grofa Khuena Hedrvarya (Ćurić 2012: 46).

\section{Umjesto zaključka}

Josip Juraj Strossmayer i Antun Gustav Matoš dva su velikana hrvatske kulture. Jedan je priznat i slavljen za života, a drugi tek poslije smrti. Poslužit ću se za kraj teksta omiljenom Matoševom metodom opisivanja Strossmayera - usporedbom Starčevića i Strossmayera publicista Josipa Horvata (bio je iznimno kritičan prema Strossmayeru) u biografskoj knjizi o Starčeviću, ali umjesto Starčevića valja zamisliti Matoša:

Kao što je Starčević [Matoš, op. a.] po običnoj ljudskoj ocjeni u svom životu zlosreća, Strossmayer je u velikoj mjeri dijete sreće. U teškim odricanjima, kroz neuspjehe 
i razočaranja Starčević [Matoš, op. a.] si mora krčiti putove u životu; Strossmayeru sve ide od ruke, s trideset i pet godina je učitelj u Augustineumu u Beču, dvorski ispovjednik, prije četrdesete postaje biskupom jedne od najbogatijih biskupija u carstvu. Neuspjesi jednog kao i uspjesi drugog prirodna su posljedica njihovih ličnosti, ne tvori ih ni sreća ni zlosreća (Horvat 1939: 275).

Za hrvatsku književnost šteta je što je Strossmayer odbio Matoševu molbu za pomoć, što mu nije dao potporu kakvu je davao primjerice M.J. Zagorki. Pomogao je mnogima koji to nisu zaslužili, a mnogi su mu za pomoć bili i vrlo - nezahvalni. Mladi Strossmayer vjerojatno bi postupio drugačije, ali ni to odbijanje nije navelo Matoša da odbaci Strossmayera.

\section{Literatura}

Badalić H., 1892, Hrvatska antologija. Umjetno pjesničtvo starijeg i novog doba, Zagreb. Brešić V., 1997, Autobiografije hrvatskih pisaca, Zagreb

Brlenić Vujić B., 2008, Antun Gustav Matoš, Josip Juraj Strossmayer i Ante Starčević, u: Lik i djelo Josipa Jurja Strossmayera, ur. S. Marijanović, Osijek, str. 531-540.

Ćurić M., 2012, Braća u poniženju, Đakovo.

Ćurić M., 2013, Što je naše od starine, đakovački pisci 18. i 19. stoljeća, Osijek.

Horvat J., 1939, Ante Starčević: kulturno-povijesna slika, Zagreb.

Jelčić D., 2008, Strossmayer i hrvatska književnost, u: Lik i djelo Josipa Jurja Strossmayera, ur. S. Marijanović, Osijek, str. 375-384.

Kosor J., 1990, Velika autobiografija, Vinkovci.

Košćak V., 1960, Strossmayerova ostavština u JAZU, Zagreb.

Kovačević Gj., 2007, Moja perva i posliednja ljubav, Đakovo.

Matoš A.G., 1967, Kritike, eseji, studije i članci, polemike, putopisi, feljtoni i impresije, ur. D. Tadijanović, M. Matković, Zagreb.

Matoš A.G., 1976, Od Zagreba do Beograda. Fragmentarne impresije, Sabrana djela, sv. 11, u: O likovnim umjetnostima. Putopisi, ur. S. Batušić, D. Jelčić, Zagreb, str. 149-158. Nemec K., 2007, Pravaštvo i hrvatska književnost, u: Jezik književnosti i književni ideologemi. Zbornik radova 35. seminara Zagrebačke slavističke škole, ur. K. Bagić, Zagreb, str. 119-129.

Oraić Tolić D., 2013, Čitanja Matoša, Zagreb.

Ostajmer B., 2005, Prilog životopisu Vatroslava Račkog: neuspješna kandidatura na saborskim izborima 1906, u: Zbornik Muzeja Đakovštine, ur. B. Bijelić, Đakovo, str. 141-164. 
Pavić K., 2008, Luka Botić u Đakovu, u: Luka Botić i Đakovo, ur. M. Ćurić, Đakovo, str. $115-138$.

Pavić M., Cepelić M., 2013, Biskup Josip Juraj Strossmayer, biskup bosansko-djakovački i sriemski, god. 1850-1900, reprint s kazalom imena i mjesta, Đakovo.

Rittig S., 1908, Luka Botić u hrvatskoj knjizi, u: idem, Kita spomenaka na grob Luke Botića, Đakovo, str. 14-16.

Smičiklas T., 1906, Nacrt života i djelâ biskupa J.J. Strossmayera, i izabrani njegovi spisi: govori, rasprave i okružnice, Zagreb.

Srakić M., 1982, Kranjčevićeva i Matoševa pisma Strossmayeru, u: idem, Đakovo i njegova okolica: zbornik Muzeja Đakovštine, Đakovo, str. 153-156.

Strossmayer J.J., 1873, Slike u Stolnoj crkvi djakovačkoj, „Glasnik biskupije djakovačko-srijemske" br. 18, str. 241-317.

Strossmayer J.J., 1874a, Slike u Stolnoj crkvi djakovačkoj, „Glasnik biskupije djakovačko-srijemske" br. 1-2, str. 19-23.

Strossmayer J.J., 1874b, Slike u Stolnoj crkvi djakovačkoj, „Vienac” br. 1, str. 14-15, br. 2, str. 29-31, br. 3, str. 44-45.

Strossmayer J.J., 1875a, Putopisne crtice, „Glasnik biskupije djakovačko-srijemske” br. $2-3$, str. $5-14$.

Strossmayer J.J., 1875b, Putopisne crtice, „Vienac” br. 4; str. 59-60; br. 5, str. 72-73; br. 6 , str. $89-92$; br. 7 , str. $106-107$; br. 9 , str. $138-140$; br. 10 , str. 155 ; br. 11, str. $168-169$; br. 12 , str. $185-187$; br. 13 , str. 205-212.

Strossmayer J.J., 1878, Slike u Stolnoj crkvi djakovačkoj, „Glasnik biskupije djakovačko-srijemske" br. 1 , str. $1-5$; br. 3 , str. $19-21$; br. 5 , str. $50-54$; br. 6 , str. $58-62$; br. 7 , str. $63-67$; br. 8 , str. $77-78$; br. 9 , str. 86 ; br. 10, str. $93-94$.

Strossmayer J.J., 2005, Izabrani književni i politički spisi I, prir. D. Jelčić, Zagreb.

Strossmayer J.J., 2006, Izabrani književni i politički spisi II, prir. D. Jelčić, Zagreb.

Strossmayer J.J., 2010, Stolna crkva u Djakovu, Đakovo.

Tordinac N., 1890, Odabrane crtice i pripoviesti, Zagreb.

Vukovac S., 2010, Marianna (Marija) Jurić Zagorka i đakovački biskup Josip Juraj

Strossmayer, „Scrinia Slavonica: godišnjak Podružnice za povijest Slavonije, Srijema i Baranje Hrvatskog instituta za povijest", sv.10, str. 244-266.

Żurek P., 2011, Poljska i Poljaci u životu Josipa Jurja Strossmayera, Slavonski Brod. 